\title{
Effect of Implementing Instructional Learning Package for Patients with Coronary Artery Disease on Compliance of Practice about Therapeutic Regimen and Barriers Affecting it
}

\author{
Soheir M. Wehaida ${ }^{1}$ Seham A. Abd El-Hay and ${ }^{2}$ Amany K. Abed Allah ${ }^{3}$ \\ ${ }^{1}$ Prof. of Medical Surgical Nursing, Faculty of Nursing, Alexandria University, \\ ${ }^{2}$ Assis. Prof. of Medical Surgical Nursing, Faculty of Nursing, Tanta University \\ ${ }^{3}$ Lecturer of Medical Surgical Nursing, Faculty of Nursing, Tanta University.
}

Abstract: Coronary Artery Disease (CAD) is a worldwide health problem. Its prevalence rate is increasing all over the world.Therapeutic regimen to be beneficial, patients must be informed about their own health and motivated to share the responsibility. So patient education is an essential part of quality of care today to avoid complications.Aim: Evaluate the effect of implementing instructional learning package for Patients with coronary artery disease on compliance of practice about therapeutic regimen and barriers affecting it.Design: A quasi experimental research design was utilized. Setting: Data were collected from Cardiovascular Department and its relevant Outpatient's Clinic of Tanta Main University Hospital. Subjects:Purposive sampling of (60) patients who are visiting the previous mentioned setting.Tools: Three tools were used to collect data: Tool (I); Biosociodemographic and knowledge assessment to evaluate patients' knowledge about therapeutic regimen, Tool (II); patients' self-reported practices regarding therapeutic regimen and Tool (III); Barriers affecting patients' compliance of therapeutic regimen. Results: Revealed that there were significant improvements of patients' knowledge mean scores and self reported practice regarding coronary artery disease and therapeutic regimen. The study also revealed common barriers those affect compliance of therapeutic regimen as; lack of knowledge, family support, getting older, visual impairment, lack of relevant assistive technology devices, pain, psychological stress afraid from injury.Conclusion The study findings revealed that implementation of instructional learning package was successful for improving patients' knowledge and self reported practice regarding therapeutic regimen. Recommendations: Further research is necessary to measure long-term adherence to healthy lifestyle among patients with CAD after the application of the educational guidelines.

Key words: Therapeutic regimen, Instructional learning package, Compliance.

Vol. 20 No. 1 (Suppl)February, 2021 


\section{Introduction:}

Cardiovascular diseases remain the biggest cause of deaths worldwide of the 57 million global deaths, 36 million were due to coronary heart disease ${ }^{(\mathbf{1})}$. Coronary artery diseases (CAD) are the leading cause of of morbidity and mortality throughout the world. It is considered one of the main reasons of disease burden in developing countries ${ }^{(2,3)}$. The world health organization estimates that at least 20 million people survive $\mathrm{CAD}$ - related heart attacks and strokes every year around the world; by 2030, almost 23.6 million people will die from CADs mainly from heart disease and stroke ${ }^{(4)}$. In Egypt, According to the most recent WHO information distributed in 2017coronary artery disease deaths in Egypt reached $24.58 \%$ of total deaths. The Death rate is 216.82 for every 100,000 of population ranks Egypt $18 \%$ in the world ${ }^{(5)}$.

Coronary artery diseases areprogressive diseases that are leading to narrowing or occlusion of the coronary arteries. Coronary artery disease occurs when atherosclerotic plaque builds up within walls of the coronary arteries leading to narrowing and appearance of the clinical manifestations of acute coronary syndrome that include angina and myocardial infarction ${ }^{(6,7)}$. Risk factors that increase the chance for developing coronary artery disease (CAD) included gender being male, increasing age, family history, high cholesterol, smoking, diabetes, hypertension, obesity, psychosocial factors, alcohol consumption, low intake of fruit and vegetables, and physical inactivity ${ }^{(8)}$. CAD has many symptoms that require ongoing monitoring for suitable health lifestyle and treatment to prevent further complications as myocardium infarction and heart failure ${ }^{(9)}$.

Despite the development of treatment strategies, CAD remains a serious health problem. Although playing pivotal roles, a proper diagnosis and implementation of recommended medication alone are not sufficient to achieve optimal results of treatment ${ }^{(\mathbf{1 0})}$. So the management of coronary artery disease must involves lifestyle modifications to be consistent with therapeutic regimen and adherence to recommended treatment which is essential to achieve intended therapeutic effect $(\mathbf{1 1 , 1 2 )}$. Therapeutic regimen education is an approach to facilitate patient understanding about the treatment of disease and the adoption of self-management behaviors and lifestyles to improve physical and psychosocial health outcomes ${ }^{(13)}$. The 
enhancement of follow up of therapeutic regimen is usually accompanied by elimination of unfavourable dietary and bad habits and increased physical activity which improve long term control of disease $^{(\mathbf{1 4})}$.

Lifestyle modifications is a critical component of patients-based strategies to control coronary artery disease symptoms and they are the first line of intervention for all patients with coronary artery disease, in combination with pharmacological treatment which is also important for the disease management to prevent short and long term complications. Therefore, lifestyle modifications should be actively performed not only before but also after starting of medications ${ }^{(15)}$. The goal of lifestyle modifications is to prevent further build up of plaque and decrease damage to blood vessels. These changes will also reduce risk of heart attack and stroke ${ }^{(16)}$.Changing unhealthy lifestyles may also lead to reductions in the risk of mortality that are greater than the benefits of some of the acute treatments for coronary disease $^{(\mathbf{1 7})}$.

Patient education is an essential aspect in enhancing compliance and can be seen as the base for the majority of patient-core intervention, education encourage patients to create decision about treatment and can develop their motivation and intent to comply with therapeutic regimen as

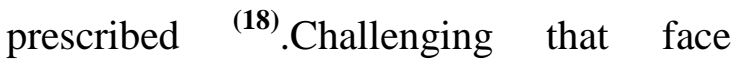
patients to change habits are generally associated with quality of life modification ${ }^{(19)}$. Education help to patient's to accuratly understanding of their disease and promotes adherence to therapeutic regimen were including; regular body weight monitoring, limitation of alcohol consumption, encouraging regular exercise, increased fruit and vegetable consumption, reduced total fat and saturated fat intake, and smoking cessation, medication administration and follow up ${ }^{(20)}$.

Nurses are in the best position to influence positively patients' lifestyle and to change their unhealthy lifestyle through health education $^{(21)}$. They help patients gain knowledge, skills and change attitude necessary to maintain therapeutic regimen because insufficient understanding of the disease may lead to emotional distress, maladaptation with the disease, nonadherence to medical treatment\& therapeutic regimen and increase disease complications (22). So educational guidelines is the best instrument to control of $\mathrm{CAD}$, it is obvious that the need for patients' awareness is very high and no longer can be delayed ${ }^{(23)}$. Therefore this 
study aimed to evaluate the effect of implementing instructional learning package for Patients with coronary artery disease on compliance of practice about therapeutic regimen and barriersaffecting it

\section{Significance of the study:-}

In today's world, most deaths are attributable to non-communicable diseases, more than one third of these deaths occur in the middle aged adults. In Egypt, the National Hypertension Project (NHP) found that overall prevalence of CAD is $18.3 \%{ }^{(24)}$. The World Health Organization illustrated that Coronary heart disease deaths in Egypt reached 107,232 or $23.14 \%$ from total deaths. Further, they reported that $80 \%$ to $90 \%$ of patients dying from $\mathrm{CAD}$ had one or more major risk factors associated with lifestyle modification non-adherence ${ }^{(25)}$. Highly percentage of deaths can be reduced by assessing and modifying risk factors and obedience to healthy lifestyle. This concern need extreme effort to progress knowledge of patients, so knowledge about lifestyle modification and therapeutic regimen adherence is an important prerequisite for an patients to implement behavioral changes towards CAD control. Aim of the study is to:-
The study was conducted to evaluate the effect of implementing instructional learning package for Patients with coronary artery disease on compliance of practice about therapeutic regimen and barriers affecting it

\section{Research hypothesis:-}

To fulfill the aim of the study the following research hypothesis were formulated

- Post implementation of instructional learning package, patients with CAD exhibit improvement in knowledge mean score regarding therapeutic regimen.

- Post implementation of instructional learning package, patients with CAD exhibit improvement in self reported practice mean scores regarding therapeutic regimen.

\section{Operational definitions:-}

Instructional Learning Package: Is a written materials developed to teach a patients concept or skill. The package's components are stated concept, pre-test, behavioral objectives, learning activities, quest activities and posttest ${ }^{(\mathbf{2 6}, 27)}$.

\section{Subjects and method:}

\section{Research design:-}

A quasi-experimental research design was utilized in this study.

\section{Setting:}

The study was conducted at the Cardiovascular Department and its relevant Outpatient's Clinic of Tanta Main University Hospital. 


\section{Subjects:}

Purposive sampling of (60) patients from previous mentioned setting. The sample size was estimated by using Epi Info Software Statistical package according to the following parameters; Total target population size $=500$ patients, confidence level $=99.9 \%$, expected frequency $=50 \%$, accepted error $=5 \%$ and confidence coefficient $=95 \%$. The acceptable sample size was 60 patients.

\section{Inclusion criteria for the patients:-}

-Age ranged between 21-60 years.

-Participants with a diagnosis of CAD for at least one month with or without other coexisting medical conditions.

\section{Tools of data collections:}

Three tools were used to collect data for this study.

Tool (I): Bio-sociodemographic and Knowledge assessment sheet:-

It was developed by the researcher to coolect pertinent data: it was comprised of:-

\section{Part (A): Socio-demographic} characteristics of patients:which includes; patient' code, age, gender, marital status, occupation, educational level,place of residency, smoking, previous instruction about therapeutic regimen.

Part (B): Patients' Clinical Data:-: It was developed by the researchers to assess patients' clinical data regarding; diagnosis, weight duration of illness, history of diabetes and hypertension, cholesterol level and experience of stress.Scoring system:clinical data scored as the following; if the problem present scored (1) and if the problem absent scored (0).

\section{Part (C): Patients' Knowledge Assessment:}

It was developed by the researchers after reviewing of the related literatures ${ }^{(\mathbf{2 8 - 3 2})}$ to assess patients' knowledge pre / 2 months post implementation of instructional learning package. It was included of the following:

Knowledge about CAD which consisted of 25 questions, it included: definition of coronary artery disease, risks factors, causes, manifestation, complication and treatment options

\section{Knowledge abouttherapeutic regimen} which consisted of 22 questions,it included: healthy diet and its' types, kind of food that should be avoided, benefit of exercise, control stress, importance of medication adherence and follow up , weight control, follow up and smoking.

\section{Scoring system of patients' knowledge:}

Two level of scoring for questions were as the following:

Correct answer was scored given of one 
Don't' know or incorrect answer was

scored given of zero

The total scoring system of patients'

knowledge (47) was calculated and

classified as the following:

- Good $\rightarrow \quad>75 \%$ of the total score

-Fair $\rightarrow \quad \geq 60 \%-75 \%$ of the total

score

- Poor $\rightarrow \quad<60 \%$ of the total score

Tool (II): Patients' self-reported

practices regarding therapeutic

regimen:

This tool was developed by the researchers

after reviewing relevant literatures ${ }^{(\mathbf{2 8 - 3 2})}$ to evaluatepatients' practice pre / 2 months post implementation of of instructional learning package regarding therapeutic regimen. It was included 17 items as;take foods low in saturated fat andfiber rich diet regularly, perform exercise regularly, check weight monitoring, take medication as prescribed and avoid smoking and stress.

The scoring system for patients' practice wascalculated as the following:

-"Correctly followed" was given a score of one

-"Not correctly followed was given zero score.

The total patients' practices score categorized into two levels
-Satisfactory $\quad \rightarrow \quad \geq 70 \%$ of the total

score

-Unsatisfactory $\rightarrow<70 \%$ of the total score

Tool (III): Barriers affecting patients' compliance of therapeutic regimen:

This tool was developed by the researchers after reviewing relevant literatures ${ }^{(33,34)}$ to elicit patients' views about barriers that affect patients' compliance to therapeutic regimen, it includes the following;

a- Patient related Barriers: as lack of knowledge, lack of family and friends support, cost of medication, level of education, lack of understanding of healthy diet, rural area as place ect....

b- Physical barriers: asvisual impairment, difficult to prepare healthy diet, Inability to stand and move easily, lack of energy and continuous fatigue, increase body weight that decrease moving, Pain in body during activity ect....

b- Psychological barriers: as difficulty of compliance of therapeutic regimen, compliance need to be dependent on others, lack of psychological health advices, lack of motivation, psychological stress and depression, afraid injure myself or have a heart attack. ect....

Scoring system, Respondents were asked to indicate their level of agreement using a 
three points Likert type scale with fix

values ranging from 1 to 3 , possible

responses per item 3 for agree, 2 for

neutral, 1 for disagree .

\section{Ethical consideration:}

An initial permission was obtained from the Head of the Cardiovascular Department and its relevant Outpatient's Clinic of Tanta Main University Hospital. Participants in this study who voluntary participate were informed about the purpose, procedure of the study and the right to withdraw from the study at any time without any rationale. Informed consent was obtained from the Participants after reading all details, confidentiality and anonymity of each subject was ensured through coding of all data and protecting the obtained data.

\section{Methods of data collection:}

1-Tools of the study were developed by the researchers after reviewing relevant literature and used to collect data. The tools were tested for its content validity by a jury of five experts in the area of Medical Surgical Nursing and Cardiovascular Medicine, Their opinions were elicited regarding tools format and consistency, it was calculated and found to be $=(95 \%)$. The reliability for the study tools was calculated by Cronbach's alpha, it was 0.94 for tool (1) and 0.99 for tool (II).

2- A pilot study was conducted before starting the current study to investigate the visibility and applicability of the developed tools, clarity of the items and the time required to fill them. It was conducted on $10 \%$ of the total sample size and was excluded from the current study. No comments regarding the difficulty of terminology, questions structure or items clarity were reported by the study sample.

3- This study was conducted at the beginning of September 2019 to December 2019.

4- Instructional learning package were developed by the researcher based on the related literature ( 35-39) and conducted through four phases (assessment and pretest, planning, implementation and evaluation) as the following:-

\section{Assessment and pretest phase;}

Pretest was carried out for patientsbefore starting instructional learning package by using tool (I) to collect baseline data and part C and Tool II were used to assess patients' knowledge and self- reported practice related to therapeutic regimen pre implementation of instructional learning 
package to determine the needs of the patients and number of the nedded sessions.

\section{Planning phase;}

The content of the instructional learning package were constructed by the researchers based on the related literature ${ }^{(35-39)}$. Behavioral objectives of the study were prepared based on theassessment phase. An illustrative structured booklet was prepared in a simple Arabic language and supported by CD contains PowerPoint, video and pictures as a guide for the patients, and different teaching methods were used as interactive lectures, discussions,demonstration. A booklet was given to each patients during sessions to refresh their knowledge and practice.Instructional learning package were conducted in (4) sessions (two sessions for theoretical knowledge and one sessions for practice) to all patients who are divided to (5) groups; each group was contained (12) patients, three days/ week, the time of each session was about two hours.

\section{Implementation phase;}

The instructional learning package was implemented in three sessions, during each session the researchers answered questions and cleared up misconceptions when voiced. Moreover, the booklet was given to each patient to attract their attention. Instructional learning package was implemented by the researchers as the following:-The First session: include information about cardiovascular disease, definition, clinical manifestation, diagnosis, treatment, complications. The second session:include information about therapeutic regimen (nutrition, exercise, weight,follow up and smoking) healthy diet and its' types, kind of food that should be avoided, benefit of exercise, control stress, importance of medication adherence and follow up. The third session: were presented through demonstration and redemonstration about perform exercise regularly, weight monitoring, take medication as prescribed and avoid smoking and stress.

\section{Evaluation Phase:}

The evaluation was carried out for each patient by using three tools which performed 2 months post implementation of instructional learning package. The results were compared to the pretest results to evaluate the effect of learning package on patients knowledge and patients' health behavios .Tool (III) was used to elicit patients' views about barriers that are face them and affect adherence to therapeutic regimen. 


\section{Methods of data analysis:}

All data were collected, coded and tabulated to statistical analysis. Statistical analysis is performed by statistical Package SPSS in general (version 20), also Microsoft office Excel is used for data handling and graphical presentationvariables. Data expressed as Mean and SD., T-test, Number and percentage and chi-square are used to determine significant for numeric variable. Pearson's Correlation analysis was used to show strength and direction of association between two quantitative variables. A probability level of $p$-value $\leq 0.01$ was adopted as a level of significance for testing the research hypotheses.

\section{Results:}

Table (1)showed the distribution of the patients according to their sociodemographic characteristics. As regards age, the table revealed that the majority of the patients $(38.3 \%)$ were in the age group of $(50 \leq 60)$ and more than half of them $(63.3 \%)$ were male. Regarding marital status, the table revealed that more than half of patients $(56.7 \%)$ weremarried. As for occupation and educational level, the table showed that $(48.3 \%)$ from patients were employee and (30.0\%) from them weresecondary education. Majority of the patients $(65.0 \%)$ were from village area.
Also the majority of them $(56.7 \%)$ were smokers and $(86.7 \%)$ had no training about therapeutic regimen.

Table (2): Showed the distribution of the coronary artery disease patients according to their medical data. The table showed that the majority of patients $(48.3 \%)$ were diagnosed as myocarduim infarction and the majority of them $(31.6 \%)$ had weight as71-80 with mean $75.13 \pm 15.212$. As regard to duration of illness majority of patients $(38.3 \%)$ suffered from disease from7 month- 1 year . Also majority of patients ( $85.0,61.7,55.0 \%)$ had history of hypertension, diagnosed with high cholesterol and diabetes mellitus respectively and also about (63.3\%) of them experieced stress.

Figure (1): Showed distribution of patients with CAD according to their knowledge about nutrition as a therapeutic regimen pre and 2 months post instructional learning package. The figure revealed that there were statistical significant improvement in patients' knowledge regarding nutrition as a therapeutic regimen from pre to post instructional learning package at $\mathrm{p}<0.05$.

Figure (2): Showed distribution of patients with CAD according to their knowledge about Exercise, weight, follow up and smoking as a therapeutic regimen pre and 
2 months post instructional learning package. The figure revealed that there were statistical significant improvement in patients' knowledge regarding Exercise, weight, follow up and smoking as a therapeutic regimen of CAD pre and post instructional learning package at $\mathrm{p}<0.05$.

Table (3): showed the mean score of the studied patients with CAD according to their knowledge about CAD pre and 2 months post instructional learning package. Highly statistically significant difference in the mean score of knowledge regarding different items of CAD related to; knowledge about risks factors and causes, knowledge about manifestation, complication and treatment and knowledge about therapeutic regimen were observed from pre to post implementation of instructional learning package with p-value $<0.05$.

Table (4): Showed distribution of patients with coronaryartery disease according to level of self reported practice pre / 2 months post implementation instructional learning package. The table showed that there were statistically significant differences among total levels of patients' self reported practice. Where the majority of the studied patients $(88.3 \%)$ had unsatisfactory level of self reported practice pre instructional learning package, whereas $(90 \%)$ of them had satisfactory level of practice after instructional learning package.

Table (5): Showed the distribution of the studied patients according to barriers affecting their compliance to therapeutic regimen. As regard to patients related barriers; the table showed that the highest percentages of patients agree that more barriers were; lack of knowledge, lack of family support, getting older and unstable living conditions, homelessness for about (46.7, 43.3, 90.0, 45.3 and $48.3 \%$ ) respectively. And highest percentages of patients disagree that cost of medication with low income.For about physical related barriers the table showed that the highest percentages of patients agree that more barriers were; visual impairment, exercises is difficult, lack of relevant assistive technology devices, pain for about (78.3, 50.0, 53.3 and 55.0\%) respectively. And highest percentages of patients disagree that physical environment that is not accessible andincrease body weight for about (43.3 and 51.7\%) respectively.Regarding psychological related barriers the table showed that the highest percentages of patients agree that more barriers were; Therapeutic regimen not important, psychological stress and depression, afraid from injury or have a 
heart attack for about (45.0, 56.7 and $48.3 \%$ ) respectively.

Table (6): Showed relationship between socio-demographic characteristics of the studied patients and their mean score of knowledge pre / 2 months post implementation of instructional learning package. The table showed that there was significant relationship between sex and smoking with mean score of knowledge pre instructional learning package $\mathrm{n}$ at $\mathrm{P}$ $<0.05$ and between marital status, Level of education and smokingwith mean score of knowledge post instructional learning package at $\mathrm{P}<0.05$

Table (7): showed the relationship between socio-demographic characteristics of the studied patients and their mean score of practice pre / 2 months post implementation of instructional learning package. The table showed that there was significant relationship between age and sex with mean score of practice pre instructional learning package at $\mathrm{P}<0.05$ and between age, sex, marital status, and smokingwith mean score of practice post instructional learning package at $\mathrm{P}<0.05$. 
Table (1): Distribution of the patients according to their socio-demographic characteristics

\begin{tabular}{|c|c|c|}
\hline \multirow[t]{2}{*}{ Variables } & \multicolumn{2}{|c|}{$\begin{array}{c}\text { The studied subjects } \\
(\mathrm{N}=60)\end{array}$} \\
\hline & $\mathbf{n}$ & $\%$ \\
\hline $\begin{array}{cc}\text { Age in years } \\
\text { - } \quad 30-\leq 40 \\
\text { - } \quad 41-\leq 50 \\
\text { - } \quad 50 \leq 60 \\
\text { - } \quad \geq 60\end{array}$ & $\begin{array}{c}10 \\
21 \\
23 \\
6\end{array}$ & $\begin{array}{l}16.7 \\
35.0 \\
38.3 \\
10.0\end{array}$ \\
\hline $\begin{aligned} & \text { Sex } \\
& \text { - } \text { Male } \\
& \text { - } \text { Female } \\
&\end{aligned}$ & $\begin{array}{l}38 \\
22\end{array}$ & $\begin{array}{l}63.3 \\
36.7\end{array}$ \\
\hline $\begin{array}{l}\text { Marital status } \\
\text { - Married } \\
\text { - Single } \\
\text { - } \text { Divorced } \\
\text { - Widow }\end{array}$ & $\begin{array}{c}34 \\
10 \\
6 \\
10\end{array}$ & $\begin{array}{l}56.7 \\
16.7 \\
10.0 \\
16.7\end{array}$ \\
\hline $\begin{array}{l}\text { Occupation } \\
\text { - Worker } \\
\text { - Employee } \\
\text { - Not work }\end{array}$ & $\begin{array}{l}19 \\
29 \\
12\end{array}$ & $\begin{array}{l}31.7 \\
48.3 \\
20.0\end{array}$ \\
\hline $\begin{array}{l}\text { Level of education } \\
\text { - Illiterate } \\
\text { - Basic(elementary) education } \\
\text { - Secondary education } \\
\text { - University education } \\
\end{array}$ & $\begin{array}{l}15 \\
15 \\
18 \\
12\end{array}$ & $\begin{array}{l}25.0 \\
25.0 \\
30.0 \\
20.0\end{array}$ \\
\hline $\begin{array}{l}\text { Place of residency } \\
\text { - Village } \\
\text { - City } \\
\end{array}$ & $\begin{array}{l}39 \\
21\end{array}$ & $\begin{array}{l}65.0 \\
35.0\end{array}$ \\
\hline $\begin{array}{c}\text { Smoking } \\
\text { - } \text { Yes } \\
\text { - } \mathrm{No} \\
\end{array}$ & $\begin{array}{l}34 \\
26\end{array}$ & $\begin{array}{l}56.7 \\
43.3\end{array}$ \\
\hline $\begin{array}{c}\text { Training about therapeutic regimen } \\
\text { - } \quad \text { Yes } \\
\text { - } \text { No } \\
\end{array}$ & $\begin{array}{c}8 \\
52\end{array}$ & $\begin{array}{l}13.3 \\
86.7\end{array}$ \\
\hline
\end{tabular}


Table (2): Distribution of patients with coronary artery disease according to their medical data

\begin{tabular}{|c|c|c|}
\hline \multirow[t]{2}{*}{ Variables } & \multicolumn{2}{|c|}{$\begin{array}{l}\text { The studied subjects } \\
(\mathbf{N}=60)\end{array}$} \\
\hline & $\mathbf{N}$ & $\%$ \\
\hline $\begin{array}{ll}\text { Diagnosis } \\
\text { - } & \text { MI } \\
\text { - } & \text { Angina } \\
\text { - } & \text { Weak in heart muscle } \\
\text { - } & \text { Atherosclerosis } \\
\text { - } & \text { DVT }\end{array}$ & $\begin{array}{c}29 \\
12 \\
13 \\
4 \\
2\end{array}$ & $\begin{array}{r}48.3 \\
20.0 \\
21.7 \\
6.7 \\
3.3\end{array}$ \\
\hline $\begin{array}{cc}\text { Weight } & \\
\text { - } & 50-60 \\
\text {. } & 61-70 \\
\text { - } & 71-80 \\
\text { - } & 81-95 \\
\end{array}$ & $\begin{array}{c}10 \\
6 \\
19 \\
25\end{array}$ & $\begin{array}{l}16.7 \\
10.0 \\
31.6 \\
41.7\end{array}$ \\
\hline Mean \pm SD & \multicolumn{2}{|c|}{$75.13 \pm 15.212$} \\
\hline 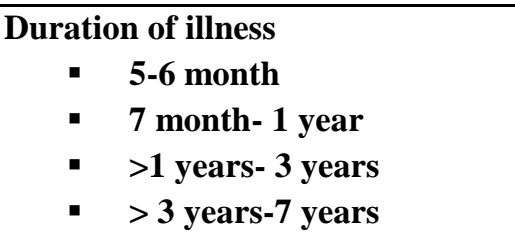 & $\begin{array}{l}12 \\
23 \\
15 \\
10\end{array}$ & $\begin{array}{l}20.0 \\
38.3 \\
25.0 \\
16.7\end{array}$ \\
\hline $\begin{array}{c}\text { History of hypertension } \\
\text { - } \quad \text { Yes } \\
\text { - } \mathrm{No}\end{array}$ & $\begin{array}{c}51 \\
9\end{array}$ & $\begin{array}{l}85.0 \\
15.0\end{array}$ \\
\hline $\begin{array}{c}\text { History of Diabetes } \\
\text { - } \quad \text { Yes } \\
\text { - } \quad \text { No } \\
\end{array}$ & $\begin{array}{l}33 \\
27\end{array}$ & $\begin{array}{l}55.0 \\
45.0\end{array}$ \\
\hline $\begin{array}{l}\text { Diagnosed with high cholesterol } \\
\text { - Yes } \\
\text { - No }\end{array}$ & $\begin{array}{l}37 \\
23\end{array}$ & $\begin{array}{l}61.7 \\
38.3\end{array}$ \\
\hline $\begin{array}{c}\text { Experience Stress } \\
\text { - Yes } \\
\text { - } \quad \text { No } \\
\end{array}$ & $\begin{array}{l}38 \\
22\end{array}$ & $\begin{array}{l}63.3 \\
36.7\end{array}$ \\
\hline
\end{tabular}




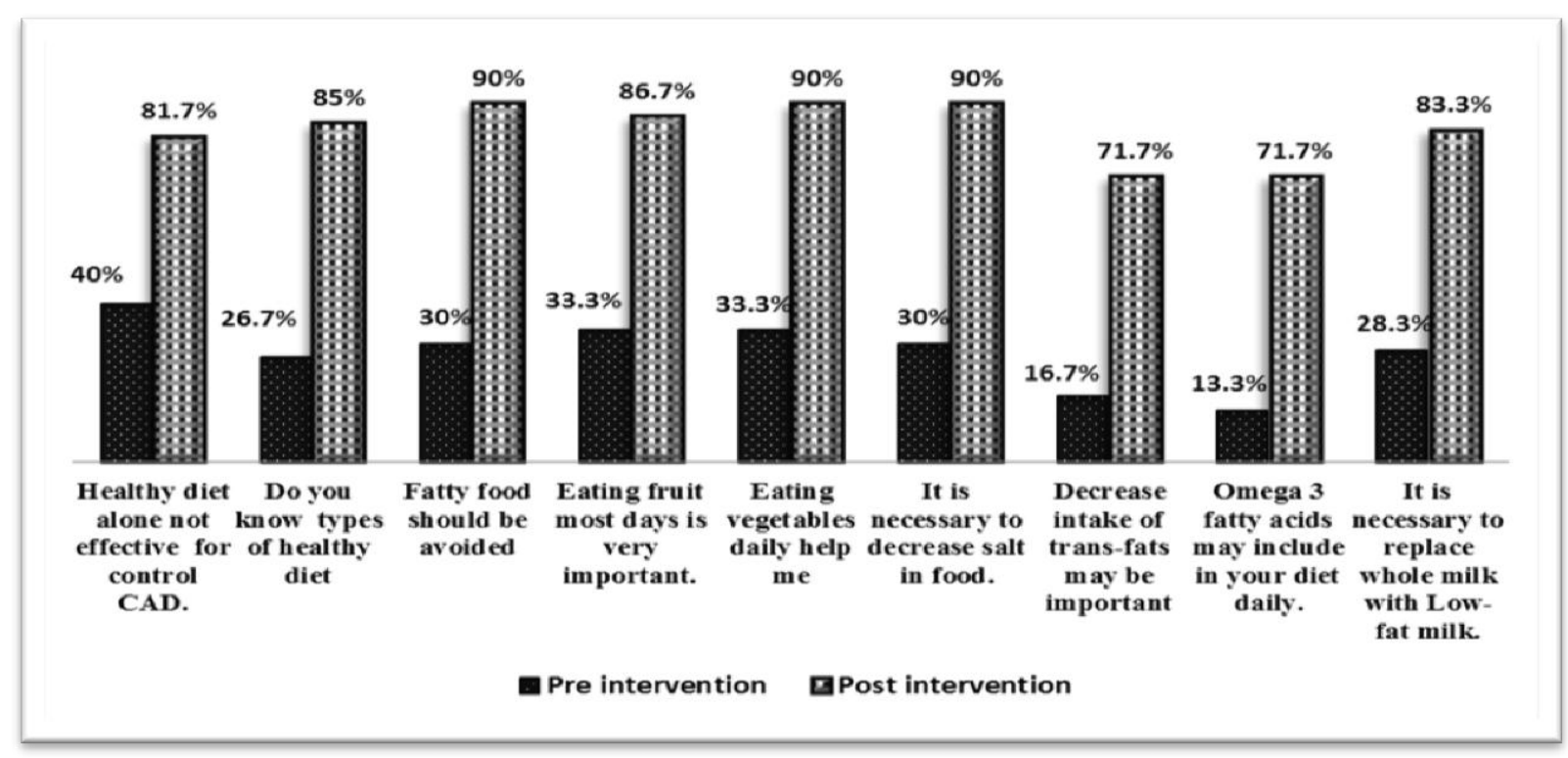

Figure (1): Distribution of patients with CAD according to their knowledge about nutrition as a therapeutic regimen pre and 2 months post instructional learning package.

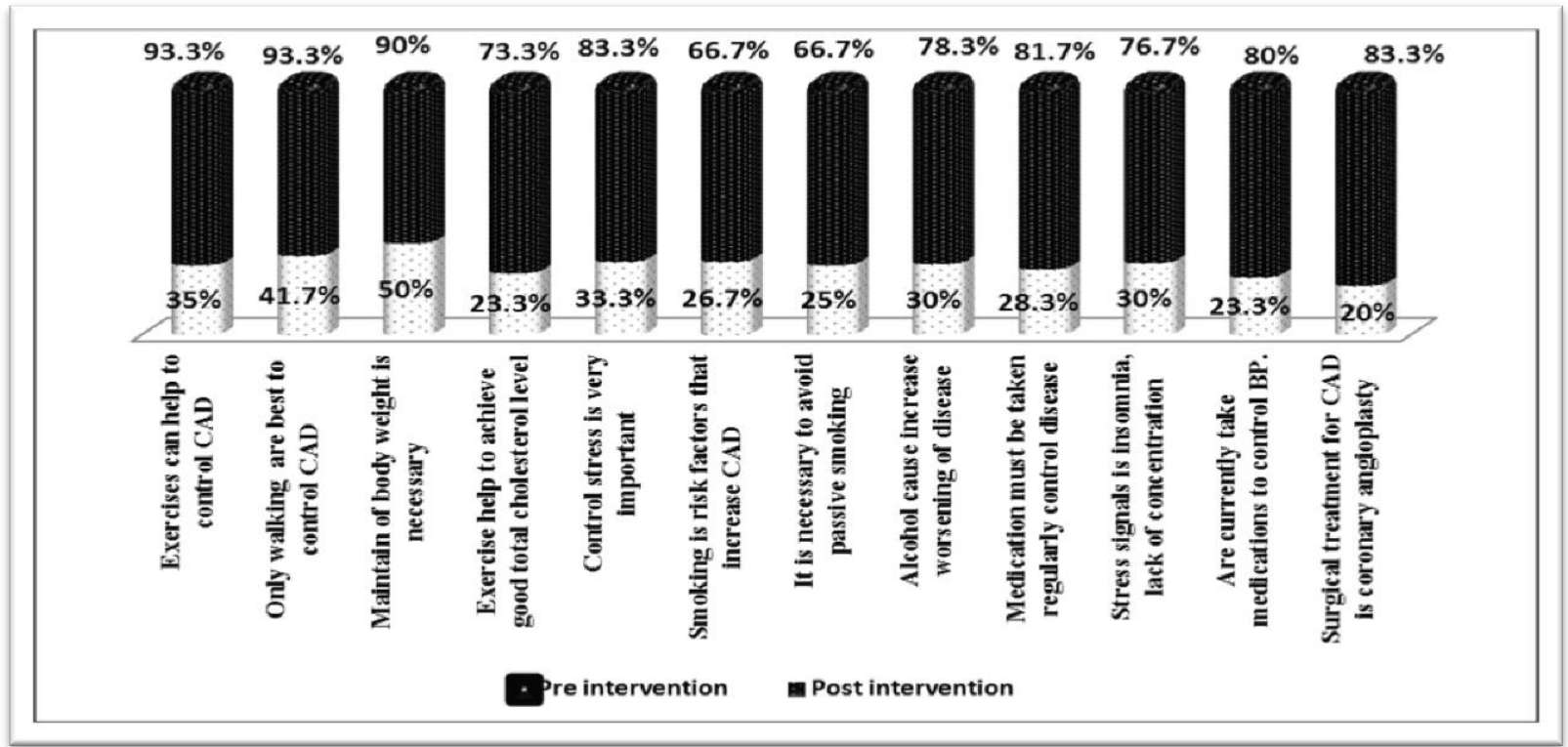

Figure (2): Distribution of patients with CAD according to their knowledge about Exercise , weight, follow up and smoking as a therapeutic regimen pre and 2 months post instructional learning package 
Table (3): Mean score of the studied patients with CAD according to their knowledge about CAD pre and post instructional learning package

\begin{tabular}{||l|c|c|c|c||}
\hline \multicolumn{1}{|c|}{ Variables } & \multicolumn{3}{c|}{ The studied subjects } \\
(N=60)
\end{tabular}

*Significant at $(\mathrm{p}<0.05)$

Table (4): Percent distribution of patients with coronaryartery disease according to level of self reported practice pre / 2 months post implementationinstructional learning package .

\begin{tabular}{|c|c|c|c|c|}
\hline \multirow{3}{*}{ Variables } & \multicolumn{4}{|c|}{$\begin{array}{l}\text { The studied subjects } \\
(\mathrm{N}=60)\end{array}$} \\
\hline & \multicolumn{2}{|c|}{$\begin{array}{c}\text { Preinstructional learning } \\
\text { package }\end{array}$} & \multicolumn{2}{|c|}{$\begin{array}{c}2 \text { months Post instructional } \\
\text { learning package }\end{array}$} \\
\hline & $\mathbf{N}$ & $\%$ & $\mathbf{N}$ & $\%$ \\
\hline Satisfactory & 7 & 11.7 & 54 & 90 \\
\hline Unsatisfactory & 53 & 88.3 & 6 & 10 \\
\hline $\begin{array}{l}\text { Range } \\
\text { Mean } \pm \text { SD }\end{array}$ & \multicolumn{2}{|c|}{$\begin{array}{c}2-5 \\
3.85 \pm 0.777\end{array}$} & \multicolumn{2}{|c|}{$\begin{array}{c}10-17 \\
13.05 \pm 1.567\end{array}$} \\
\hline $\mathbf{P}$ & \multicolumn{4}{|c|}{$\begin{array}{l}\text { 6.760 } \\
0.000^{* * *}\end{array}$} \\
\hline
\end{tabular}

* Significant at $\mathbf{P}<0.05$. 
Table (5): Distribution of the studied patients according to barriers affecting their compliance to therapeutic regimen.

\begin{tabular}{|c|c|c|c|c|c|c|}
\hline \multirow{2}{*}{$\begin{array}{l}\text { Barriers affecting compliance of } \\
\text { therapeutic regimen }\end{array}$} & \multicolumn{2}{|c|}{ Agree } & \multicolumn{2}{|c|}{ Natural } & \multicolumn{2}{|c|}{ Disagree } \\
\hline & $\mathbf{N}$ & $\%$ & $\mathbf{N}$ & $\%$ & $\mathbf{N}$ & $\%$ \\
\hline \multicolumn{7}{|c|}{ Patient related Barriers } \\
\hline Lack of knowledge about disease & 28 & 46.7 & 8 & 13.3 & 24 & 40.0 \\
\hline Lack of family and friends support & 26 & 43.3 & 12 & 20.0 & 22 & 36.7 \\
\hline getting older so exercise can be risky & 54 & 90.0 & 6 & 10.0 & - & - \\
\hline Cost of medication with low income & 2 & 3.3 & 8 & 13.3 & 50 & 83.3 \\
\hline Low level of education & 4 & 6.7 & 46 & 76.7 & 10 & 16.7 \\
\hline Unstable living conditions, homelessness & 29 & 48.3 & 16 & 26.7 & 15 & 25.0 \\
\hline Rural area obstacles to follow instruction & 8 & 13.3 & 44 & 73.3 & 8 & 13.3 \\
\hline \multicolumn{7}{|c|}{ Physical related barriers } \\
\hline visual impairment & 47 & 78.3 & 8 & 13.3 & 5 & 8.3 \\
\hline difficult to prepare healthy diet & 14 & 23.3 & 37 & 61.7 & 9 & 15.0 \\
\hline physical environment that is not accessible. & 25 & 41.7 & 9 & 15.0 & 26 & 43.3 \\
\hline Making physical exercises is difficult for me & 30 & 50.0 & 5 & 8.3 & 25 & 41.7 \\
\hline lack of relevant assistive technology devices & 32 & 53.3 & 7 & 11.7 & 21 & 35.0 \\
\hline Inability to stand and move easily & 16 & 26.7 & 27 & 45.0 & 17 & 28.3 \\
\hline Increase body weight that decrease moving & 7 & 11.7 & 22 & 36.7 & 31 & 51.7 \\
\hline Pain in body during activity & 33 & 55.0 & 14 & 23.3 & 13 & 21.7 \\
\hline lack of confidence in ability to be physically active & 18 & 30.0 & 31 & 51.7 & 11 & 18.3 \\
\hline \multicolumn{7}{|c|}{ Psychologicalrelated barriers } \\
\hline Disease leads to be dependent on others & 8 & 13.3 & 36 & 60.0 & 16 & 26.7 \\
\hline Disease limit my life & 4 & 6.7 & 39 & 63.3 & 18 & 30.0 \\
\hline Lack of psychological health advices & 14 & 23.3 & 31 & 51.7 & 15 & 25.0 \\
\hline Therapeutic regimen not important & 27 & 45.0 & 19 & 31.7 & 14 & 23.3 \\
\hline psychological stress and depression & 34 & 56.7 & 6 & 10.0 & 20 & 33.3 \\
\hline I'm afraid I might injure myself or have a heart att & 29 & 48.3 & 27 & 45.0 & 4 & 6.7 \\
\hline Lack of motivation & 26 & 43.3 & 30 & 50.0 & 4 & 6.7 \\
\hline
\end{tabular}


Table (6): Relationship between socio-demographic characteristics of the studied patients and their mean score of knowledge pre / 2 months post implementation of instructional learning package.

\begin{tabular}{|c|c|c|c|c|c|c|}
\hline \multirow{3}{*}{ Variables } & \multicolumn{6}{|c|}{$\begin{array}{l}\text { The studied subjects } \\
\qquad(\mathrm{N}=60)\end{array}$} \\
\hline & \multicolumn{3}{|c|}{$\begin{array}{c}\text { Preinstructional learning } \\
\text { package }\end{array}$} & \multicolumn{3}{|c|}{$\begin{array}{c}2 \text { months Post } \\
\text { instructional learning } \\
\text { package }\end{array}$} \\
\hline & $\mathbf{n}$ & $\begin{array}{c}\text { Mean } \\
\text { rank }\end{array}$ & $\begin{array}{c}\text { P- } \\
\text { value }\end{array}$ & $\mathbf{n}$ & $\begin{array}{c}\text { Mean } \\
\text { rank }\end{array}$ & $\begin{array}{c}\mathbf{P}- \\
\text { value }\end{array}$ \\
\hline $\begin{array}{cl}\text { Age in years } \\
\text { : } & 30-\leq 40 \\
\text { : } & 41-\leq 50 \\
\text { : } & 50 \leq 60 \\
\text { - } & \geq 60\end{array}$ & $\begin{array}{c}10 \\
21 \\
23 \\
6\end{array}$ & $\begin{array}{l}30.60 \\
35.10 \\
29.96 \\
16.33\end{array}$ & 0.137 & $\begin{array}{c}10 \\
21 \\
23 \\
6\end{array}$ & $\begin{array}{l}46.30 \\
24.40 \\
31.72 \\
20.83\end{array}$ & 0.005 \\
\hline $\begin{aligned} \text { Sex } & \\
\text { - } & \text { Male } \\
\text { - } & \text { Female }\end{aligned}$ & $\begin{array}{l}38 \\
22\end{array}$ & $\begin{array}{l}26.79 \\
36.91\end{array}$ & $0.029 *$ & $\begin{array}{l}38 \\
22\end{array}$ & $\begin{array}{l}27.79 \\
35.18\end{array}$ & 0.109 \\
\hline $\begin{array}{ll}\text { Marital status } \\
\text { - } \text { Married } \\
\text { - Single } \\
\text { - } \text { Divorced } \\
\text { - Widow }\end{array}$ & $\begin{array}{c}34 \\
10 \\
6 \\
10\end{array}$ & $\begin{array}{l}33.26 \\
29.40 \\
32.67 \\
20.90\end{array}$ & 0.253 & $\begin{array}{c}34 \\
10 \\
6 \\
10\end{array}$ & $\begin{array}{l}32.21 \\
45.90 \\
18.00 \\
16.80\end{array}$ & $0.000 *$ \\
\hline $\begin{array}{l}\text { Occupation } \\
\text { - Worker } \\
\text { - Employee } \\
\text { - Not work }\end{array}$ & $\begin{array}{l}19 \\
29 \\
12\end{array}$ & $\begin{array}{l}26.29 \\
30.64 \\
36.83\end{array}$ & 0.255 & $\begin{array}{l}19 \\
29 \\
12\end{array}$ & $\begin{array}{l}27.34 \\
33.50 \\
28.25\end{array}$ & 0.423 \\
\hline $\begin{array}{l}\text { Level of education } \\
\text { - Illiterate } \\
\text { - Basic education } \\
\text { - Secondary education } \\
\text { - University education }\end{array}$ & $\begin{array}{l}15 \\
15 \\
18 \\
12\end{array}$ & $\begin{array}{l}21.53 \\
31.63 \\
33.44 \\
35.88\end{array}$ & 0.123 & $\begin{array}{l}15 \\
15 \\
18 \\
12 \\
\end{array}$ & $\begin{array}{l}21.57 \\
35.43 \\
38.89 \\
22.92 \\
\end{array}$ & $0.008 *$ \\
\hline $\begin{array}{l}\text { Place of residency } \\
\text { - Village } \\
\text { - City }\end{array}$ & $\begin{array}{l}39 \\
21\end{array}$ & $\begin{array}{l}31.55 \\
28.55\end{array}$ & 0.521 & $\begin{array}{l}39 \\
21\end{array}$ & $\begin{array}{l}30.09 \\
31.26\end{array}$ & 0.802 \\
\hline $\begin{array}{c}\text { Smoking } \\
\text { : Yes } \\
\text { - No }\end{array}$ & $\begin{array}{l}26 \\
34\end{array}$ & $\begin{array}{l}25.37 \\
34.43\end{array}$ & $0.044^{*}$ & $\begin{array}{l}26 \\
34\end{array}$ & $\begin{array}{l}22.04 \\
36.97\end{array}$ & $0.001 *$ \\
\hline
\end{tabular}

* Significant at $\mathbf{P}<\mathbf{0 . 0 5}$. 
Table (7): Relationship between socio-demographic characteristics of the studied patients and their mean score of practice pre / 2 months post implementation of instructional learning package.

\begin{tabular}{|c|c|c|c|c|c|c|}
\hline \multirow{3}{*}{ Variables } & \multicolumn{6}{|c|}{$\begin{array}{l}\text { The studied subjects } \\
(\mathrm{N}=60)\end{array}$} \\
\hline & \multicolumn{3}{|c|}{$\begin{array}{c}\text { Pre instructional learning } \\
\text { package }\end{array}$} & \multicolumn{3}{|c|}{$\begin{array}{c}2 \text { months Post } \\
\text { instructional learning } \\
\text { package }\end{array}$} \\
\hline & $\mathbf{n}$ & $\begin{array}{c}\text { Mean } \\
\text { rank }\end{array}$ & $\begin{array}{c}\mathrm{P}- \\
\text { value }\end{array}$ & $\mathbf{n}$ & $\begin{array}{c}\text { Mean } \\
\text { rank }\end{array}$ & $\begin{array}{c}\text { P- } \\
\text { value }\end{array}$ \\
\hline $\begin{array}{c}\text { Age in years } \\
\text { - } \quad 30-\leq 40 \\
\text { - } \quad 41-\leq 50 \\
\text { - } \quad 50 \leq 60 \\
\text { - } \geq 60-70 \\
\end{array}$ & $\begin{array}{c}10 \\
21 \\
23 \\
6\end{array}$ & $\begin{array}{l}24.80 \\
23.90 \\
39.13 \\
30.00 \\
\end{array}$ & $0.010^{*}$ & $\begin{array}{c}10 \\
21 \\
23 \\
6 \\
\end{array}$ & $\begin{array}{l}45.10 \\
26.24 \\
28.65 \\
28.17 \\
\end{array}$ & $0.025^{*}$ \\
\hline $\begin{aligned} \text { Sex } & \\
\text { - } & \text { Male } \\
\text { - } & \text { Female }\end{aligned}$ & $\begin{array}{l}38 \\
22\end{array}$ & $\begin{array}{l}33.82 \\
24.77\end{array}$ & $0.037 *$ & $\begin{array}{l}38 \\
22\end{array}$ & $\begin{array}{l}25.34 \\
39.41\end{array}$ & $0.002 *$ \\
\hline $\begin{array}{ll}\text { Marital status } \\
\text { - } \text { Married } \\
\text { - Single } \\
\text { - } \text { Divorced } \\
\text { - } \text { Widow } \\
\end{array}$ & $\begin{array}{c}34 \\
10 \\
6 \\
10\end{array}$ & $\begin{array}{l}32.21 \\
28.90 \\
40.00 \\
20.60 \\
\end{array}$ & 0.098 & $\begin{array}{c}34 \\
10 \\
6 \\
10 \\
\end{array}$ & $\begin{array}{l}27.41 \\
47.00 \\
28.00 \\
26.00 \\
\end{array}$ & $0.009 *$ \\
\hline $\begin{array}{ll}\text { Occupation } \\
\text { - Worker } \\
\text { - Employee } \\
\text { - Not work }\end{array}$ & $\begin{array}{l}19 \\
29 \\
12\end{array}$ & $\begin{array}{l}31.05 \\
29.60 \\
31.79\end{array}$ & 0.910 & $\begin{array}{l}19 \\
29 \\
12\end{array}$ & $\begin{array}{l}20.32 \\
34.38 \\
37.25\end{array}$ & $0.005 *$ \\
\hline $\begin{array}{l}\text { Level of education } \\
\text { - Illiterate } \\
\text { - Basic education } \\
\text { - Secondary education } \\
\text { - University education }\end{array}$ & $\begin{array}{l}15 \\
15 \\
18 \\
12 \\
\end{array}$ & $\begin{array}{l}30.43 \\
30.70 \\
27.33 \\
35.08\end{array}$ & 0.646 & $\begin{array}{l}15 \\
15 \\
18 \\
12 \\
\end{array}$ & $\begin{array}{l}28.13 \\
28.00 \\
34.56 \\
30.50 \\
\end{array}$ & 0.641 \\
\hline $\begin{array}{l}\text { Place of residency } \\
\text { - Village } \\
\text { - City }\end{array}$ & $\begin{array}{l}39 \\
21\end{array}$ & $\begin{array}{l}29.83 \\
31.74\end{array}$ & 0.663 & $\begin{array}{l}39 \\
21\end{array}$ & $\begin{array}{l}29.21 \\
32.90\end{array}$ & 0.416 \\
\hline $\begin{array}{c}\text { Smoking } \\
\text { : Yes } \\
\text {. No }\end{array}$ & $\begin{array}{l}26 \\
34\end{array}$ & $\begin{array}{l}30.77 \\
30.29\end{array}$ & 0.910 & $\begin{array}{l}26 \\
34\end{array}$ & $\begin{array}{c}24.21 \\
35.31\end{array}$ & $0.011^{*}$ \\
\hline
\end{tabular}

* Significant at $\mathbf{P}<0.05$. 


\section{Discussion}

Coronary Artery Disease is a serious cardiovascular disorder and the most important single cause of death in the affluent countries of the world $^{(40)}$. Nowadays, the incidence of coronary artery disease is increasing in different countries due to the changes in life style and increase in life expectancies, so prevention of coronary artery disease must involve a multifactorial approach and needs to be ongoing throughout the life span. The person who has modifiable risk factors should be encouraged and motivated to make lifestyle changes to reduce the risk of coronary artery disease ${ }^{(41)}$. So this study was aimed to evaluate the effect of implementing instructional learning package for Patients with coronary artery disease on compliance of practice about therapeutic regimen and barriers affecting it.

Concerning to socio-demographic data of the coronary artery disease studied patients, the study results revealed that the majority of the patients were in the age group of $(50 \leq 60)$ years and more than half of them were male and married. Also the majority of the patients were employee, have secondary education and live in village area. In addition to the majority of them were smokers and have no training about therapeutic regimen regarding coronary artery disease. Regarding medical data, the table showed that the majority of patients were diagnosed as myocarduim infarction with duration of illness from7 month- 1 year. Also majority of patients had history of hypertension, high cholesterol, diabetes mellitus and stress.

These findings were in the same line with Muhamad et al., (2012) ${ }^{(42)}$ who reported that the majority of patients with CAD. Most of them had secondary education and unemployed, around $60 \%$ of them were either active or passive smoker. Hypertension was the highest reported risk in the family of the respondents followed by diabetes mellitus.Also these findings were in the same line with Bhattarai and Neupane (2018) ${ }^{(43)}$ who reported that majority of patients with CAD age groups were of 60 or above age groups, more than $50 \%$ of the patients were female, highest percentage of them were literate with secondary level. Morover Attarchi et al., (2012) (44) reported that most of the participants were male; married and education level of most of them was above high school diploma. The mean age of them was 29.33 years. The clinical status of the participants included the history of heart disease and DM. 
The present study revealed that there were highly statistically significant difference in the mean score of knowledge regarding different items of CAD related to; knowledge about risk factors, causes, manifestation, complication, treatment and knowledge about therapeutic regimen were observed from pre to post implementation of instructional learning package. Improvement in the knowledge mean score about CAD among patients may be attributed to that the education which included a combination of verbal information and booklet help improve patients'knowledge, in addition to use of open discussion during the application of the instructional learning package and giving written information may have been contributed to the success of the intervention. These findings were in the same line with Kotseva etal., (2016) ${ }^{(45)}$ who reported that in their study, the results suggest that a change in coronary heart disease patients' lifestyle and their knowledge are insufficient. Furthermore, not attending any form of rehabilitation program lowers the level of risk control.

Moreover these findings were in the same line with Tawalbeh and Ahmad (2013) ${ }^{(46)}$ who reported that results in their study indicated that the knowledge among patients with coronary artery disease significantly improved one month post the application of the cardiac educational program. Also Jin etal., (2008) (47) reported that patients with CAD will benefit from specific knowledge of risk factors to adhere prescribed medication after cardiac events (knowing the risk factors improve adherence to advice on lifestyle changes and medication).In addition to John and Haseena (2015) ${ }^{(\mathbf{3 9})}$ reported that in their study majority of subjects have average knowledge regarding $\mathrm{CAD}, 23.5 \%$ of subjects have poor knowledge and only $21.5 \%$ have good knowledge regarding CAD. Ahmed etal., (2013) ${ }^{(48)}$ alsoreported that patients' knowledge was analyzed and revealed that more than half of participants had low level of knowledge about MI, and less than $10 \%$ of participants had very high level of knowledge.

The present study revealed that there was highly statistically significant difference among total levels of patients' self reported practice regarding adherence to therapeutic regimen after instructional learning package. Improvement in the practice behviors about CAD among patients may be attributed to thatinstructional learning package providebetter lifestyle choices for patients, such as not smoking, doing exercises, and eating a healthy diet. These 
findings were in the same line withMohammad etal., (2018) ${ }^{(49)}$ who reported that self reported practice that done by the patients were vigorous work in their working hour and take plenty of vegetables. However, other practices were not frequently carried out where the mean of practice score was less than half of the total scores. AlsoMuhamad etal., (2012) ${ }^{(\mathbf{5 0})}$ reported that only a few of the subjects use special food or supplements. This might be because the patient was not aware of the importance of the special diet as therapeutic regimen.

Moreover Ramachandran etal., $\mathbf{( 2 0 1 6 )}^{(\mathbf{5 1})}$ reported thatawareness about CAD was seen to be positively associated with improvement practice of healthy lifestyle behaviors, though findings on the predictive relationship of knowledge of risk factors on healthy lifestyle behaviors in women seem to be divided. In addition to Plach etal., (1996) ${ }^{(52)}$ reported that patients who attended a single 2-hour postdischarge education class had significantly higher knowledge of coronary artery disease and coronary artery disease risk factors. Knowledge may better prepare people to increase health-promoting behaviors. Bhattarai1 and Neupane (2018) ${ }^{(53)}$ mentioned thatpractices for healthy lifestyle of CAD diseases determined by patients, where $31.7 \%$ of them had monitored blood pressure. Similarly, ,only $7.9 \%$ follow healthy diet. Furthermore, blood cholesterol was done only by $3.9 \%$.

Regarding barriers that are affecting compliance of therapeutic regimen, the present study revealed that many barriers affect follow up of therapeutic regimem as following; for about patients barriers, the highest percentages of patients agree that more barriers were; lack of knowledge, lack of family support, getting older and unstable living conditions.For about physical barriers the highest percentages of patients agree that more barriers were; visual impairment, exercises is difficult, lack of relevant assistive technology devices, pain.Regarding psychological barriers the highest percentages of patients agree that more barriers were; therapeutic regimen not important, psychological stress and depression, afraid from injury or have a heart attack.

These findings were in the same line withSalah (2004) ${ }^{(34)}$ who reported that patients with unstable living conditions such as diabetes mellitus and another chronic illness had unsatisfactory level of adhering with their therapeutic regimen. Also Gendy etal., (2013) ${ }^{(54)}$ reported that in their study, as regard to the common 
physical factors that hinder patients' compliance with therapeutic regimen the study revealed that more than two thirds of patients reported that they have physical problems such as pain \& fatigue. In addition to Perk etal., (2015) ${ }^{(55)}$ reported that in their study, lack of time and psychological stress associated with hospitalization might result in poor compliance of therapeutic regimen.

Moreover Gendy etal., (2008) suggested that patients aged 80 and over were less likely to be compliant with their prescribed therapeutic regimen and medication, but the participants in that particular study had also physical disabilities which limit its follow up of healthy lifestyle. Ponnusankar etal., (2004) ${ }^{(57)}$ suggested that Patient's knowledge about their disease and treatment is not always adequate. Some patients lack understanding of the role their therapies play in the treatment; others lack knowledge about the disease and consequences of poor compliance. In addition to Lee and Keeffe (2011) reported thatpatients who have social support from family, friends, or caregivers to assist with medication regimens have better adherence to therapeutic regimen. On the other hand unstable living environments, limited access to health care, lack of financial resources, cost of medication, and burdensome work schedules have all been associated with decreased adherence rates therapeutic regimen.

The finding of the study showed that there was significant relationship between sex and smoking with mean score of knowledge pre intervention and between marital status, level of education and smokingwith mean score of knowledge post learning package. Also there was significant relationship between age and sex with mean score of practice pre learning package and between age, sex, marital status, and smokingwith mean score of practice post learning package. These findings were in the same line withAttarchi et al., (2012) ${ }^{(44)}$ This study showed a significant correlation between the level of knowledge about coronary artery disease and age, salary, level of education, family history of diabetes.On the other hand this result was in contrast with Rachel and Baby (2014) ${ }^{(59)}$. Who reported that there was no significant association between the attitude, or health behavior and their selected demographic variables in both experimental and control groups. Hence, the research hypothesis H4 was rejected. 


\section{Conclusions:-}

In the light of the current study, it can be concluded that: There were statistical significant improvements of patients' knowledge and self reported practice mean score regarding coronary artery disease and therapeutic regimen post learning package. Also the study revealed common barriers those affecting compliance of therapeutic regimen which includes; lack of knowledge, lack of family support, getting older and unstable living conditions, visual impairment, inabilitiesexercises is difficult, lack of relevant assistive technology devices, pain, psychological stress and depression, afraid from injury or have a heart attack. Moreover there were statistical significant positive relationship between patients' knowledge and self reported practice and sociodemographic data.

\section{Recommendations}

Based upon results of the current study, the following recommendations were suggested:

-Patients`education should be considered a fundamental part of patients during therapeutic management.

-Further research is necessary to assess long-term adherence to therapeutic regimen among patients with $\mathrm{CAD}$ after the application of the educational guidelines.

-A study can be replicated on a larger package sample thereby findings can be generalized .

\section{References}

1. World Health Organization, Causes of death: 2008. Available at Url:http://www.who.inthealthinfo./gl obal_burden_ disease/CAD_2008_ sources_methods_pdf.

\section{Gomar F, Quilis C, Leischik R,} LuciaA. Epidemiology of coronary heart disease and acute coronary syndrome.Annals of Translational Medicine 2016; 4 (13): 256.

3.Thomas A, Bitton A, Anand S. GesselSand MurphyA.Growing Epidemic of Coronary Heart Disease in Low- and Middle-Income Countries. Current Problems in Cardiology 2010 ; 35 (2): 72-115 .

4. Abd El Hafeez N, Hafez M, Sanhoury M. Effect of Changing Position on Patient Outcomes after Transfemoral Diagnostic Cardiac Catheterization, IOSR Journal of Nursing and Health Science, 2018; $7(6): 32-42$.

5.Yusuf $\mathbf{F}$. The inter heart case-control study, Lancet, , 2004; 364(3): 93752. 
6.Katz M, Ness S. Coronary Artery Disease. Retrieved 11, August, 2015, from https: // pdfs. semanticscholar.org/./ffc4bfff546ccff19 $85 \mathrm{~d} 5 \mathrm{bb} 37 \mathrm{a} 2 \mathrm{e} 68$.

7.Williams R. Cardiovascular disease in African American women: A health care disparities issue. J Natl Med Assoc. 2009; 101(6): 536-40.

\section{Barnett T, Li Yoong T, Pinikahana}

J, Si-Yen T. Fluid compliance among patients having hemodialysis: Can an educational programme make a difference?Journal of Advanced Nursing, 2008; 619(8): 300-06.

\section{Leal J, Luengo-Fernández R,} Petersen S, Rayner M. Economic burden of cardiovascular diseases in the Enlarged European Union. Eur heart J. 2006; 27(13):610-9.

10.Nichols M, Townsend N, Scarborough P, Rayner $\mathbf{M}$. Cardiovascular disease in Europe 2014: epidemiological update. Eur Heart J. 2014; 35(12):2950-59.

11.Neubeck L, Freedman S, Clark A, Briffa T, Bauman A, Redfern J. Participating in cardiac rehabilitation: a systematic review and metasynthesis of qualitative data. Eur J Prev Cardiol. 2012; 19(3):494503.
12.Kubica A, Grześk G, Sienkiewicz W, Kozinski M, Grześk E, Goch A.[Compliance, concordance, adherence in chronic disease]. Folia Cardiol Excerpta. 2010;5(9):54-57. Polish.

13-Lagger G, Pataky Z, Golay A. Efficacy of therapeutic patient education in chronic diseases and obesity.Patient Educ Couns. 2010; 79( 7):283-86.

\section{4-Stewart K, Mc Namara K, George} J. Challenges in measuring medication adherence: experiences from a controlled trial. Int $\mathrm{J}$ Clin Pharm. 2014; 36(1): 15-19.

15-J.H.S.Guidelines for the Management of Hypertension Guidelines (JSH 2014), Hypertension Research, lifestyle modification, 2014; 37:286-290.

16-Susan K, Anu T, Achu G, Soumya K, Vijayakumar T. Antihypertensive Drug Compliance across Clinic and Community Settings, in Thiruvananthapuram, South India. Health Sciences 2012;1(3):266-80..

\section{7-Iestra J, Kromhout D, Van der}

Schouw Y. Effect size estimates of lifestyle and dietary changes on allcause mortality in coronary artery 
disease patients: a systematic review.

Circulation. 2005;112(6):924-34.

\section{8-Taha A, Mahmoud M, Mohamed}

E. Factors Affecting Esophageal Varices Patients Compliance to Therapeutic Regimen and Suggested Guidelines, IOSR Journal of Nursing a nd Health Science, 2017;6 (3): 8898.

19-Teo K, Lear S, Islam S. Prevalence of a healthy lifestyle among individuals with cardiovascular disease in high-, middle- and lowincome countries. The prospective urban and rural epidemiology (PURE).JAMA.2013;309(32):161321.

\section{0-Abd El-Hay S, El Mezayen S.} Knowledge and Perceptions Related to Hypertension, Lifestyle Behavior Modifications and Challenges That Facing Hypertensive Patients, Journal of Nursing and Health Science, 2015; 4 (6): 15-26

21-Olson L, Mara C. hand book of long term core administration and policy, CRC press Teylor \&Francis group available at:http//www.Crcpress.com USA, 2008.

\section{2-Alm-Roijer C, Fridlund B, Stagmo}

M, Erhardet E. Knowing your risk factors for coronary heart disease improves adherence to advice on lifestyle changes and medication. Journal of Cardiovascular Nursing, 2006; 21(5): 24-31.

\section{3-Vaccarino V, Borgatta A, Gallus} G, Sirturi C. Prevalence of coronary heart disease risk factors in a northern Italian male and female employees. European Heart Journal, 2003;16(6):761.

24-El-Moselhy E, Mohammed A, Abd El-Aziz A, Sadek I, Hagrass S, Farag G.Coronary Artery Disease among Elderly Egyptian Patients: Socio-Demographic, Lifestyle, Psychosocial, Medical\& Biochemical Risk Factors, American Journal of Gerontology and Geriatrics, 2018; 1 ( 2).

\section{5-Gaziano T, Bitton A, Anand S.} Growing epidemic of coronary heart disease in low- and middle-income countries. Curr Probl Cardiol 2010; 35: $72-115$.

26- Alshahad H. Design Simple Instructional Package of Arabic Language Learning for Non-Arabic Speakers, Scientific Journal of KerbalaUniversity, 2013; 11 (1) .5570. 
27-Stuart O, David F, Thomas L, Samuel L, David G, David N. Oncology of Infancy and Childhood E-Book. Philadelphia, PA: Elsevier Health Sciences. 2009;1258

28-Jensen L, Moser D. Gender differences in knowledge, attitudes, and beliefs about heart disease. Nurs Clin North Am. 2008;43(6):77-104.

29-Kang Y, Yang I, Kim N. Correlates of health behaviors in patients with coronary artery disease. Asian Nurs Res (Korean Soc Nurs Sci) 2010;4:45-55.

30-Van Bekkum J, Hilton S. Primary care nurses' experiences of how the mass media influence frontline healthcare in the UK. BMC Fam Pract. 2013;14(10):178-80

\section{1-Almas A, Hameed A, Sultan F.} Knowledge of coronary artery disease (CAD) risk factors and coronary intervention among university students., J Pak Med Assoc. 2008;58(10):553-7.

32-Lin K, Middleton J. Rethinking Aspirin for the Primary Prevention of Cardiovascular Disease. Am Fam Physician. 2019;1;99(11):670-671.

33-Frazier G, Klein W. Prevalence and Management of Hypertension in Acute Coronary Syndrome Patients
Varies By Sex, American Heart Journal, (2006); 150 (6):1260-1267.

34-Salah A. Discharge Plan Model for Coronary Artery Disease Patients.Unpublished Master Thesis, Medical Surgical Nursing, Faculty of Nursing, Ain Shams University, 2004.

35-Mahabadi A,Möhlenkamp S, Lehmann N, Kälsch H, Dykun I, Pundt N, Moebus S, Jöckel KH, Erbel R., Recall Study Investigators. CAC Score Improves Coronary and CV Risk Assessment Above Statin Indication by ESC and AHA/ACC Primary Prevention Guidelines. JAC CCardiovascImaging. 2017;10(2):14 3-153.

36- Liu C, Latham N. Progressive resistance strength training for improving physical function in older adults. Cochrane Database Syst Rev. 2009; 8(3):2759.

37-Rajkumar A, Reena M. Diagnosis Of Heart Disease Using Datamining Algorithm. J Comput Sci Technol, 2010;10(5):39-43.

\section{8-Centers for Disease Control and} Prevention (CDC). Prevalence of coronary heart disease-United States, 2006-2010. MMWR Morb Mortal Wkly Rep. 2011;60(40):1377-1381. 
39-Zeidan R, Farah R, Chahine M.

Prevalence and correlates of coronary heart disease: first population-based study in Lebanon. Vasc Health Risk Manag. 2016;12(5):75-84.

40- John J, Haseena T. Compliance with Therapeutic Regimen in Patients with Coronary Artery Disease, International Journal of Science and Research (IJSR), 2015;4(11):385.

41-Susan L, Erika S.Cardiac nursing.6th ed. Philadelphia: LippincottPublications; 2010 ;810- 901

42-Muhamad R, Yahya R, Yusoff $H$.

Knowledge, Attitude and Practice on Cardiovascular Disease among Women in North-Eastcoast Malaysia, International Journal of Collaborative Research on Internal Medicine \& Public Health, 2012;4(1): 85-98.

\section{3-Bhattarai}

$\mathbf{S}$,

NeupaneP.,Knowledge and practices on prevention of coronary artery diseases in Nepalese community: A cross-sectional from five different cities in Nepal, Nepalese Heart Journal 2018; 15(2), 33-35.

44-Attarchi M, Mohammadi S, Nojomi M, Labbafinejad Y.
Knowledge and Practice Assessment of Workers in a Pharmaceutical Company about Prevention of Coronary Artery Disease, Acta Medica Iranica, 2012;50 (10): 699.

\section{5-Kotseva K, Wood D, De Bacquer}

D. a European Society of Cardiology survey on the lifestyle, risk factor and therapeutic management of coronary patients from 24 European countries. Eur J Prev Cardiol. 2016; 23: 636-648.

46-Tawalbeh L, Ahmad M.The Effect of Cardiac Education on Knowledge and Adherence to Healthy Lifestyle, Clinical Nursing Research, 2014; 23(3): 245-258.

\section{7-Jin J, Sklar G, MinSen V, Chuen} S. Ther Clin Risk Manag Factors affecting therapeutic compliance: A review from the patient's perspective, 2008;4(1):269-86.

\section{8-Ahmed E, Youssif M, Ayasreh I,} Al-mawajdeh $\mathbf{N}$. assess the risk factors and knowledge on modification of lifestyle among patients who have experienced acute myocardial infarction in taif, international journal of medical science and public health, 2013; 2 (2): 354. 
49-Mohammad N, Rahman

N, Haque M. Knowledge, attitude, and practice regarding the risk of cardiovascular diseases in patients attending outpatient clinic in Kuantan, Malaysia, journal of pharmacy and bioallied sciences, $2018 ; 10$ (1): 7-14.

50-Muhamad R, Yahya R, Yusoff $H$.

Knowledge, attitude and practice on cardiovascular disease among women in north-east coast Malaysia. Int. Journal Collab Res Intern Med Public Health 2012;4:85-98.

\section{1- Ramachandran $\quad H, \quad X i$} Wu V, Kowitlawakul Y, Wang W

- Awareness, Knowledge and Healthy Lifestyle Behaviors Related to Coronary Heart Disease Among Women: An Integrative Review, Heart Lung, 2016;45(3):173-85.

\section{2-Plach S, Wierenga M, Heidrich}

S. Effect of a Postdischarge Education Class on Coronary Artery Disease Knowledge and SelfReported Health-Promoting Behaviors, Heart Lung 1996;25(5):367-72.

\section{3-Bhattarai1 S, Neupane $P$.} Knowledge and practices on prevention of coronary artery diseases in Nepalese community: A cross-sectional from five different cities in Nepal, Nepalese Heart Journal 2018;15(2): 33-5.
54-Gendy J, Mahrous F, El ghatey A. Guidelines for the Factors Affecting Compliance of Patients with Coronary Artery Bypass Graft toward Therapeutic Regimen, Journal of American Science 2013;9(12): 729-742.

\section{5- Perk J. Hambraeus $K$ and Burell}

G. Study of Patient Information after percutaneous Coronary Intervention (SPICI): should prevention programmes become more effective? EuroIntervention.2015; 10(6): 1-7.

\section{6-Jin J, Edward G, Min Sen Oh} V, Chuen Li S. Factors affecting therapeutic compliance: A review from the patient's perspective, Ther Clin Risk Manag. 2008 ; 4(1): 269286.

57-Ponnusankar S, Surulivelrajan M, Anandamoorthy N. Assessment of impact of medication counseling on patients' medication knowledge and compliance in an outpatient clinic in South India. Patient Educ Couns. 2004;54(9):55-60.

58- Lee M, Keeffe B. Study of adherence comes to the treatment of chronic hepatitis B. (editorial) Journal of Hepatology 2011(54) :6875.

59-Rachel H, Baby P. Effectiveness of Structured Interventional Strategy on Knowledge, Attitude and health behavior regarding selected modifiable coronary artery disease 
risk factors among adolescents in selected schools, Journal of Nursing and Health Science, 2014;3(6) 01-07. 